\title{
Hemodynamic Characteristics of the Centrally Mediated Pressor Activities of Angiotensin
}

\author{
Kiyoshi Inoue, M.D., Harold Smulyan, M.D., \\ and Robert H. Eich, M.D.
}

\section{SUMMARY}

In 19 vagotomized open-chest dogs with sodium pentobarbital anesthesia, hemodynamic effects were evaluated following injection of angiotensin into either vertebral artery using a fine catheter tied into place. Doses of $5 \mathrm{ng} / \mathrm{Kg}$ produced an increase in both right ventricular stroke volume and the maximum rate of right ventricular pressure rise, without an effect on the left ventricle, mean pulmonary artery pressure (MPAP) mean systemic arterial pressure (MAP) or heart rate (HR). Doses of $10 \mathrm{ng} / \mathrm{Kg}$ caused an increase in both right and left ventricular stroke volume and $\mathrm{dp} / \mathrm{dt}$ without an effect on MAP, MPAP, or HR. Doses from 15 to $50 \mathrm{ng} / \mathrm{Kg}$ raised arterial pressure, which was accompanied by an augmented $\mathrm{HR}$, stroke volume and $\mathrm{dp} / \mathrm{dt}$ of both ventricles. These effects, however, could not be reproduced by similar intravenous or intracarotid artery doses which provided an equipressor response. These results may suggest that the central nervous system activity of angiotensin operates by stimulation of sympathetic, predominantly beta adrenergic sites.

\section{Additional lndexing Words:}

Right heart bypass preparation Beta adrenergic blockade Stellectomy Carotid occlusion

GOR many years angiotensin was thought to have a single direct action on 4 vascular smooth muscle, which increased peripheral vascular resistance and accounted for its pressor activity. Recently other actions of angiotensin have been described. It raises the levels of circulating catecholamines ${ }^{1 /}$ and has been shown to stimulate both the central ${ }^{2-4)}$ and peripheral ${ }^{5-8)}$ alpha adrenergic vasoconstrictor mechanisms. The role of adrenergic activity

From the Department of Medicine, State University of New York, Upstate Medical Center, Syracuse, New York.

This work was supported by a grant from U.S. Public Health Service, National Institute of Health, \# HE 05410.

Mailing Address: Dr. Inoue's current address is the Second Department of Internal Medicine, University of Tokyo Hospital, 7-3-1, Hongo, Bunkyo-ku, Tokyo, Japan.

This work was in part presented at the 42nd Scientific Session of the American Heart Association in November 1969 at Dallas, Texas.

Received for publication February 7, 1973. 
following intravenous angiotensin is uncertain since some workers believe it to make a significant contribution to the pressor effect $\left.{ }^{3,4}, 4,9\right)-13$ ) and others do not. ${ }^{14-17)}$ The pressor activity, which can be demonstrated only by relatively large intravenous doses of angiotensin, is of clinical importance in the few patients with a renal vascular disease. ${ }^{18), 19)}$ Small, physiological amounts of angiotensin operating through these adrenergic mechanisms ${ }^{20), 21)}$ may be responsible in part for the fine regulation of the blood pressure, cardiac output and its tissue distribution in normal individuals. ${ }^{22}$ )

The central nervous system mediated adrenergic activity of angiotensin is especially interesting since it may represent a non-neurogenic signal from the peripheral circulation to the circulatory control centers in the brain. Administration of angiotensin into the circulation of the brain stem has produced alpha adrenergic stimulation demonstrated by an increase in the contractile force of the nictitating membrane of the cat. ${ }^{91}$ But the circulatory responses to this stimulus have been also associated with beta adrenergic stimulation-increased heart rate ${ }^{91,10), 23)}$ and cardiac output, ${ }^{24}$ ) and action unlike the responses to intravenous angiotensin. With regard to the central nervous system sites of angiotensin sensitivity, Cranston and his associates ${ }^{23}$ ) have reported that at least one part of the brain activated by angiotensin was located within the area of distribution of the vertebral artery, although the physiological significance of this locus is uncertain.

Aside from these studies, there is little detailed information available which describes the hemodynamic basis for angiotensin's central nervous system activity. The present investigation was undertaken to confirm the activity of low angiotensin doses in the portion of the brain perfused by the vertebral artery, compare that activity to the response when angiotensin was given intravenously, and gain understanding of the mechanism of central nervous system angiotensin action.

\section{Methods}

Nineteen dogs weighing 16 to $28 \mathrm{Kg}$ were anesthetized with intravenous doses of $30 \mathrm{mg} / \mathrm{Kg}$ of pentobarbital sodium, and respirations maintained by a Harvard respirator. The cervical vagi were severed bilaterally. The chest was opened through a midline incision, the pericardium opened, and the heart suspended in a pericardial cradle. Either vertebral artery was ligated between its origin from the subclavian artery and its entrance into the transverse canal of the 6th cervical vertebrae. A long fine polyethylene catheter was inserted into the artery and advanced so that the tip of the catheter lay near its 2 nd or the 3 rd spinal branch. A single dose of angiotensin (valyl, 5 octa peptide, Ciba), varying from 5 to $50 \mathrm{ng} / \mathrm{Kg}$, was delivered into the artery through the catheter. A constant volume not greater than $0.1 \mathrm{ml}$ was used for the injection and this volume was rinsed into the vertebral circula- 
tion with $0.5 \mathrm{ml}$ of saline within $5 \mathrm{sec}$. Sufficient time was allowed between repeated injections to permit all measured variables to return to control levels. Pressures in both ventricles, pulmonary and femoral arteries were measured using Statham model P-23 Db strain gauges. A large bore cannula was inserted into the left ventricle through the apical dimple and another sewn into the right ventricle through a stab wound. The stroke volumes of the right and left ventricles were monitored using electromagnetic flowmeter probes (Statham model 40001) around the pulmonary artery and the aorta. The end diastolic flow signal was taken to represent zero flow. Contractility was estimated by measuring the maximum rate of the right and left ventricular pressure rises $(\mathrm{dp} / \mathrm{dt})$ using an R.C. circuit. Changes in the stroke volume and $\mathrm{dp} / \mathrm{dt}$ were expressed as percent change from control which was taken as 100 percent. Both venricular pressures were also recorded at high gain for monitoring the changes in ventricular end diastolic pressures. All data were recorded simultaneously using an Electronics for Medicine model DR-8, multichannel oscilloscopic photographic recorder at a paper speed of $75 \mathrm{~mm}$ or $100 \mathrm{~mm}$ per second.

Approximately $30 \mathrm{~min}$ after completion of these preparations, the following 3 groups of studies were carried out.

Group 1-7 dogs. Hemodynamic responses were monitored following injection of angiotensin into the vertebral artery. A single dose of angiotensin, 5, 10, 15, 30, or $50 \mathrm{ng} / \mathrm{Kg}$, was used for each injection. Changes in right ventricular hemodynamics were evaluated in detail using 5 dogs, in 3 of which the right atrial pressure was measured using a low level strain gauge (Statham model P-23 BB). In 2 dogs the changes in pulmonary vascular resistance were studied. This was accomplished by measurement of the pulmonary artery perfusion pressure while pulmonary arterial blood flow was held constant using a right heart bypass preparation. The right heart bypass was carried out by draining caval and coronary sinus flow into a heated reservoir and pumping this blood at a constant rate into the pulmonary artery using a Sarns roller pump. The pump speed was held constant to provide a flow of $1,500 \mathrm{ml}$ per minute. The results of intravertebral angiotensin injection were compared with those obtained by similar injections into the common carotid artery, pulmonary artery, right ventricle and femoral vein.

Group 2-7 dogs. Hemodynamic effects produced by angiotensin injected into the vertebral artery were compared to those following intravenous administration. Angiotensin doses 15 to 30 times more concentrated ranging from 0.1 to $1.0 \mu \mathrm{g} / \mathrm{Kg}$ were used intravenously to provide an approximately equipressor effect, compared with intravertebral injection. In addition, the different adrenergic mechanisms involved in the pressor responses produced by intravertebral vs intravenous angiotensin were evaluated. The effect of propranolol $(0.5 \mathrm{mg} / \mathrm{Kg})$ in $4 \mathrm{dogs}$, and bilateral stellectomy in 3 dogs on the responses to vertebral artery injection were compared to that occurring following the intravenous administration of equipressor doses of angiotensin.

Group 3-5 dogs. The pressor response to bilateral carotid artery occlusion was measured and this effect was compared to the carotid occlusion response following intravenous and intravertebral artery injection of equipressor doses of angiotensin. Bilateral carotid artery occlusion was applied $10 \mathrm{sec}$ after the vertebral artery injection and $30 \mathrm{sec}$ following intravenous injections. These time intervals were found to be optimal for the peak response to angiotensin alone for each injection site. Simi- 
larly, these procedures were repeated after the administration of propranolol $(0.5 \mathrm{mg} /$ $\mathrm{Kg}$ ) in these dogs.

\section{RESULTS}

\section{A: Hemodynamic Effects of Angiotensin Injected into the Vertebral Artery}

The results obtained in Group 1 are summarized in Table I. Doses of $5 \mathrm{ng} / \mathrm{Kg}$ did not increase mean arterial pressure. They did, however, produce a significant increase of $7 \mathrm{mmHg}( \pm 0.6 \mathrm{SE})$ in the right ventricular systolic pressure without an effect on the left ventricular pressure, mean pulmonary artery pressure, or heart rate. This effect appeared $10 \mathrm{sec}$ after angiotensin injection and had disappeared approximately 5 min later. There was also an increase $(19 \% \pm 0.8 \mathrm{SE})$ in right ventricular stroke volume (RV-SV) and an increase $(40 \% \pm 1.8 \mathrm{SE})$ in $\mathrm{dp} / \mathrm{dt}$ of the right ventricle (RV-dp/dt).

Table I. Hemodynamic Effects of Angiotensin Injected into the Vertebral Artery

Left Ventricular Hemodynamics

\begin{tabular}{|c|c|c|c|c|c|c|}
\hline \multirow{2}{*}{$\begin{array}{l}\text { Dose of } \\
\text { Angiotensin } \\
\text { (ng/Kg) }\end{array}$} & \multirow{2}{*}{$\begin{array}{c}\text { MAP } \\
(\mathrm{mmHg}) \\
\mathrm{Mcan} \pm \mathrm{SE}\end{array}$} & \multirow{2}{*}{$\begin{array}{c}\text { HR } \\
\text { (beats/min) } \\
\text { Mean } \pm S E\end{array}$} & \multirow{2}{*}{$\begin{array}{c}\text { LVSP } \\
(\mathrm{mmHg}) \\
\text { Mean } \pm \mathrm{SE}\end{array}$} & \multirow{2}{*}{$\begin{array}{c}\text { LVEDP } \\
(\mathrm{mmHg}) \\
\text { Mean } \pm \mathrm{SE}\end{array}$} & \multicolumn{2}{|c|}{$\begin{array}{l}\text { Percent Increase } \\
(+ \text { Mean } \pm S E)\end{array}$} \\
\hline & & & & & $\mathrm{LV} \mathrm{dp} / \mathrm{dt}$ & LVSV \\
\hline control & $91 \pm 3.2$ & $160 \pm 6.2$ & $130 \pm 4.1$ & $3.7 \pm 0.6$ & 0 & 0 \\
\hline 5 & $92 \pm 4.1$ & $163 \pm 6.8$ & $131 \pm 4.8$ & $3.8 \pm 0.8$ & 0 & 0 \\
\hline 10 & $101 \pm 4.3$ & $168 \pm 7.1$ & $149 \pm 5.1^{*}$ & $3.8 \pm 0.7$ & $26 \pm 3.2^{*}$ & $11 \pm 1.3 *$ \\
\hline 15 & $110 \pm 3.8^{*}$ & $171 \pm 9.8$ & $161 \pm 4.8^{*}$ & $4.1 \pm 0.8$ & $43 \pm 2.8^{*}$ & $18 \pm 1.4^{*}$ \\
\hline 30 & $124 \pm 5.1^{*}$ & $178 \pm 6.3^{*}$ & $193 \pm 6.7 *$ & $4.1 \pm 0.7$ & $58 \pm 4.1^{*}$ & $21 \pm 1.6^{*}$ \\
\hline 50 & $138 \pm 6.2^{*}$ & $188 \pm 4.9 *$ & $196 \pm 7.1^{*}$ & $4.8 \pm 0.6$ & $74 \pm 4.3 *$ & $23 \pm 1.8^{*}$ \\
\hline
\end{tabular}

Right Ventricular Hemodynamics

\begin{tabular}{c|c|c|c|c|c|c}
\hline $\begin{array}{c}\text { Dose of } \\
\text { Angiotensin } \\
\text { (ng/Kg) }\end{array}$ & $\begin{array}{c}\text { MPAP } \\
(\mathrm{mmHg}) \\
\text { Mean } \pm \text { SE }\end{array}$ & $\begin{array}{c}\text { MRAP } \\
(\mathrm{mmHg}) \\
\text { Mean } \pm \text { SE }\end{array}$ & $\begin{array}{c}\text { RVSP } \\
(\mathrm{mmHg}) \\
\text { Mean } \pm \text { SE }\end{array}$ & $\begin{array}{c}\text { RVEDP } \\
(\mathrm{mmHg}) \\
\text { Mean } \pm \text { SE }\end{array}$ & \multicolumn{2}{|c}{$\begin{array}{c}\text { Percent Increase } \\
\text { (+Mean } \pm \text { SE) }\end{array}$} \\
\hline control & $11 \pm 3.1$ & $2.2 \pm 0.6$ & $14 \pm 2.8$ & $2.2 \pm 0.3$ & 0 & 0 \\
5 & $12 \pm 3.6$ & $2.2 \pm 0.4$ & $21 \pm 1.8^{*}$ & $2.3 \pm 0.4$ & $40 \pm 1.8 *$ & $19 \pm 0.8^{*}$ \\
10 & $12 \pm 3.8$ & $3.3 \pm 0.9$ & $22 \pm 2.1^{*}$ & $2.6 \pm 0.3$ & $48 \pm 2.3^{*}$ & $22 \pm 1.1^{*}$ \\
15 & $13 \pm 2.8$ & $3.8 \pm 0.7$ & $23 \pm 2.6^{*}$ & $3.1 \pm 0.7$ & $51 \pm 2.7 *$ & $22 \pm 1.7^{*}$ \\
30 & $12 \pm 3.1$ & $4.1 \pm 0.7$ & $23 \pm 2.8^{*}$ & $3.4 \pm 0.6$ & $56 \pm 2.7^{*}$ & $21 \pm 2.3^{*}$ \\
50 & $13 \pm 3.7$ & $4.9 \pm 1.1$ & $24 \pm 2.8^{*}$ & $3.4 \pm 0.9$ & $60 \pm 1.9^{*}$ & $24 \pm 1.1^{*}$
\end{tabular}

Abbreviations: $M A P=$ mean systemic arterial pressure, $H R=$ heart rate, $M P A P=$ mean pulmonary artery pressure, $\mathrm{MRAP}=$ mean right atrial pressure, $\mathrm{LV}=$ left ventricle, $\mathrm{RV}=\mathrm{right}$ ventricle, $\mathrm{SP}=$ systolic pressure, $\mathrm{EDP}=$ end diastolic pressure, $\mathrm{SV}=$ stroke volume, $\mathrm{SE}=$ standard error, ${ }^{*}=$ significant difference from control $(P<0.05)$ 

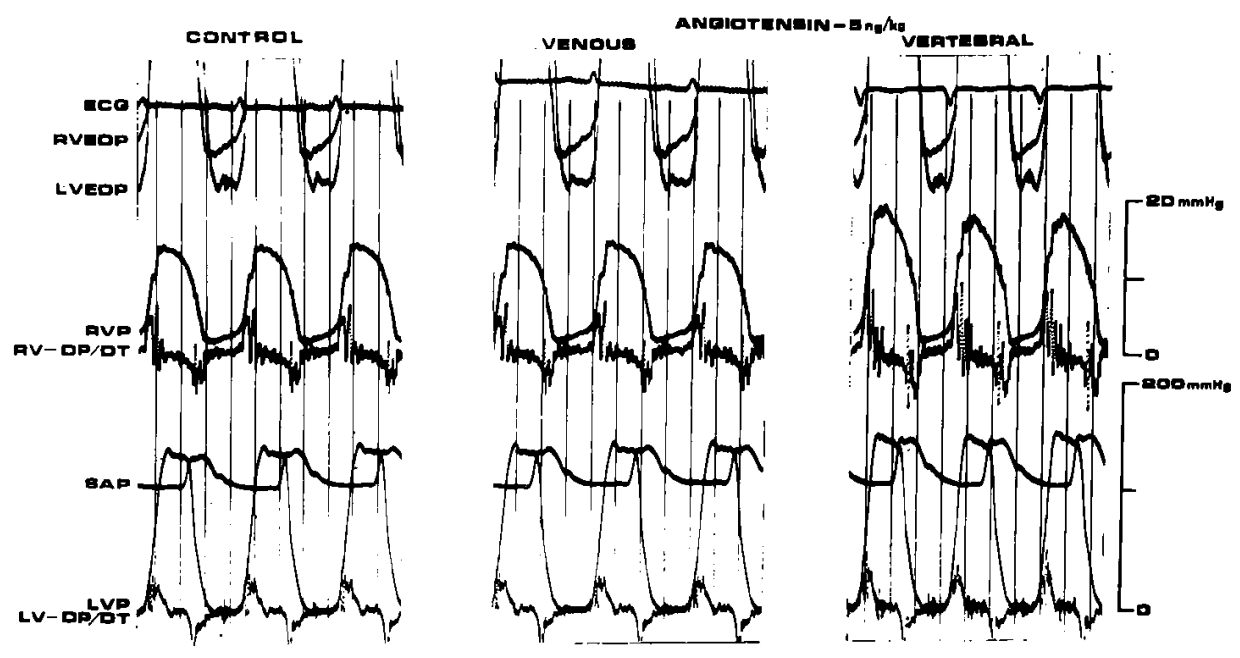

Fig. 1. Tracings compare the effects $34 \mathrm{sec}$ following intravenous and 10 sec after intravertebral artery injection of angiotensin, equal doses of $5 \mathrm{ng} / \mathrm{Kg}$, and demonstrate the selective increase in right ventricular (RV) systolic pressure and RV-dp/dt. Abbreviations: EGG=electrocardiogram, RV (LV) $\mathrm{EDP}=$ right (left) ventricular end diastolic pressure, $\mathrm{RV}(\mathrm{LV}) \mathrm{P}=$ right (left) ventricular pressure, $\mathbf{S A P}=$ systemic arterial pressure.

Despite a rise in right ventricular systolic pressure, no significant increase in mean right atrial pressure occurred. Although not shown in this table, pulmonary vascular resistance, as estimated by the changes in pulmonary perfusion pressure with constant cardiac output, was unaffected by intravertebral angiotensin in 2 additional dogs. The effect of angiotensin $5 \mathrm{ng} / \mathrm{Kg}$ into the vertebral artery, however, could not be reproduced by similar injections into the common carotid artery, pulmonary artery, right ventricle or femoral vein. The records shown in Fig. 1 compare the effects of $5 \mathrm{ng} / \mathrm{Kg}$ of angiotensin administered intravenously with those of the same dose injected into the vertebral artery, and demonstrate the occurrence of the isolated right ventricular response. In this dog, the response was accompanied by a transient change in the pattern of electrocardiogram, which however, was not systematically evaluated in this study.

Doses of $10 \mathrm{ng} / \mathrm{Kg}$ increased both right and left ventricular systolic pressure without an effect on the levels of mean systemic and pulmonary arterial pressure. These rises in the systolic pressures of both ventricles were associated with a significant increase in both right and left ventricular stroke volume and $\mathrm{dp} / \mathrm{dt}$. Similar effects, however, were not observed when these doses $(10 \mathrm{ng} / \mathrm{Kg})$ of angiotensin were injected into the common carotid artery or femoral vein. 
Larger angiotensin doses, ranging from 15 to $50 \mathrm{ng} / \mathrm{Kg}$ produced a rise in mean systemic arterial pressure, which was associated with increases in both ventricular stroke volume and $\mathrm{dp} / \mathrm{dt}$. The increase in heart rate was variable at the doses of 15 to $30 \mathrm{ng} / \mathrm{Kg}$, but did occur at $50 \mathrm{ng} / \mathrm{Kg}$. All doses used for vertebral artery injection when given intravenously or into the common carotid artery produced no consistent rise in systemic arterial pressure.

B: Comparison of the Hemodynamic Effects of Equipressor Angiotensin Doses Given Intravenously and into the Vertebral Artery

The results obtained in Group 2 are summarized and illustrated in Fig. 2. This figure shows the dose response relationship of heart rate, left ventricular storke volume and $\mathrm{dp} / \mathrm{dt}$ to intravenous and vertebral artery injections of an
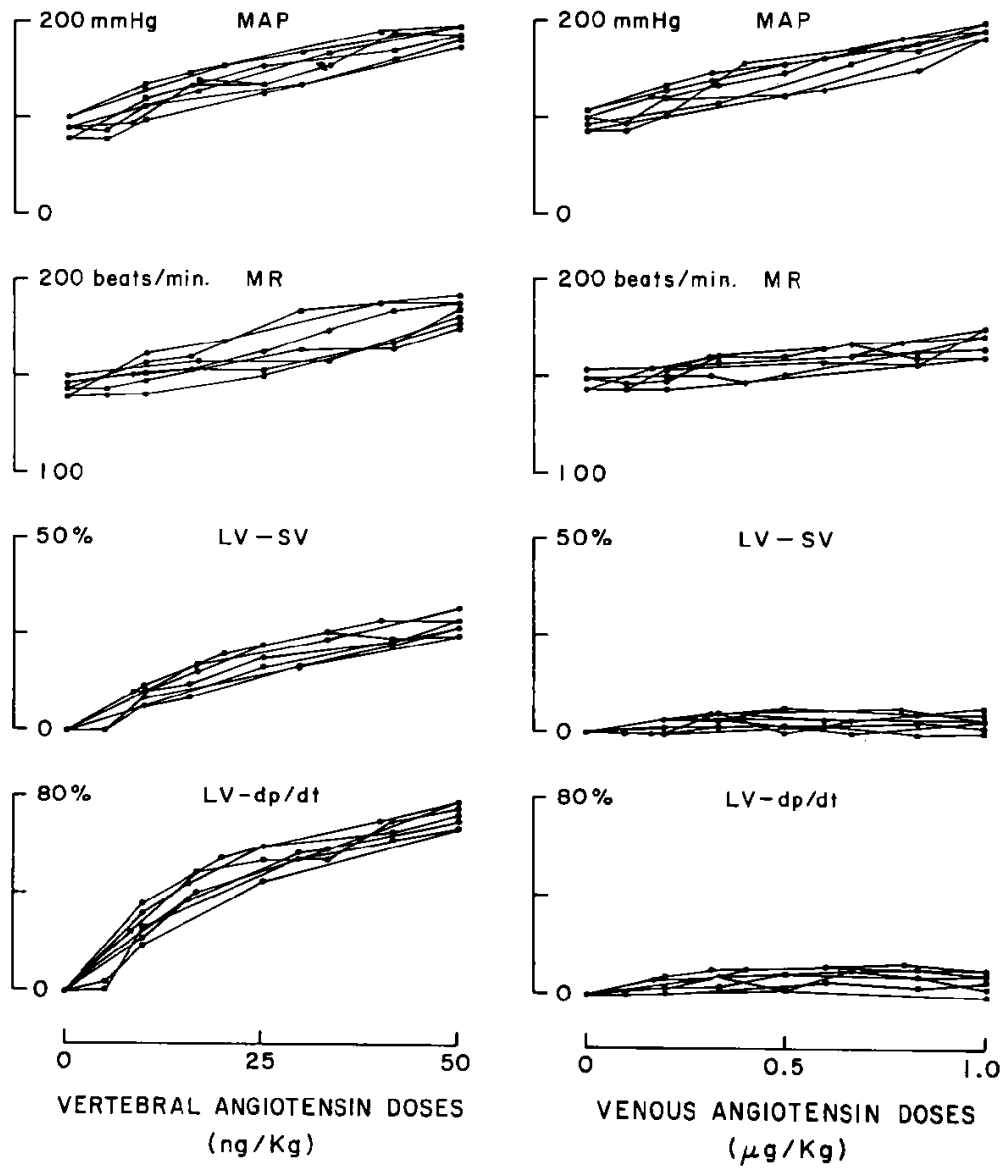

Fig. 2. This compares the dose response relationship of heart rate (HR), left ventricular stroke volume (LV-SV) and LV-dp/dt produced by giving approximately equipressor doses intravenously and into the vertebral artery. $\mathrm{MAP}=$ mean systemic arterial pressure. 
equipressor doses in 7 dogs. The stroke volume and $\mathrm{dp} / \mathrm{dt}$ of the left ventricle are expressed as the percent increase over control. Dose dependent increases in the mean systemic arterial pressure are similar with intravenous and intravertebral artery administration. The pressor effect following vertebral artery injection, however, is associated with a dose-dependent increase in the heart rate, stroke volume and $\mathrm{dp} / \mathrm{dt}$ of the left ventricle, while those of intravenous doses are not. The recordings shown in Fig. 3 are typical of the results obtained by injecting equipressor angiotensin doses intravenously and into the vertebral artery. As seen in this figure, similar increases in mean arterial pressure were obtained. The vertebral artery injection, however, increased contraction velocities of both ventricles, as measured by the maximum rate of ventricular pressure rise-(dp/dt), and shortened the duration of systole. The right ventricular systolic pressure was also augmented. Although now shown in this figure, the stroke volume of both ventricles increased more following the vertebral artery injection than it did after intravenous administration of equipressor doses. Apparent from this figure is the increase in mean arterial pressure following the vertebral artery injection which seems to be due to a greater increase in systolic pressure, while that of intravenous injection to a greater rise in diastolic pressure.

The effect of beta adrenergic blockade and bilateral stellectomy on these hemodynamic effects are illustrated in Fig. 4. The rise in systemic arterial pressure following vertebral artery injection of doses $20 \mathrm{ng} / \mathrm{Kg}$ of angiotensin

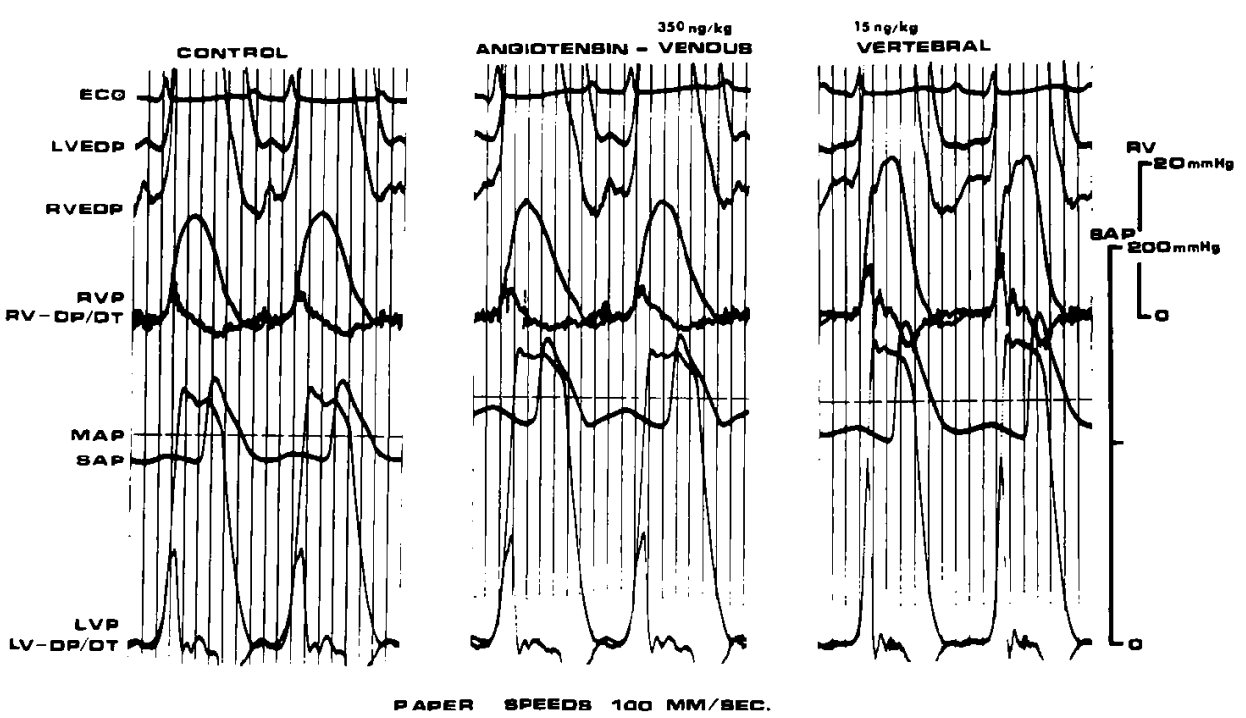

Fig. 3. Tracings compare the effects $40 \mathrm{sec}$ following intravenous and $12 \mathrm{sec}$ after intravertebral artery injection of equipressor doses of angiotensin. Abbreviations are as in Fig. 1. 


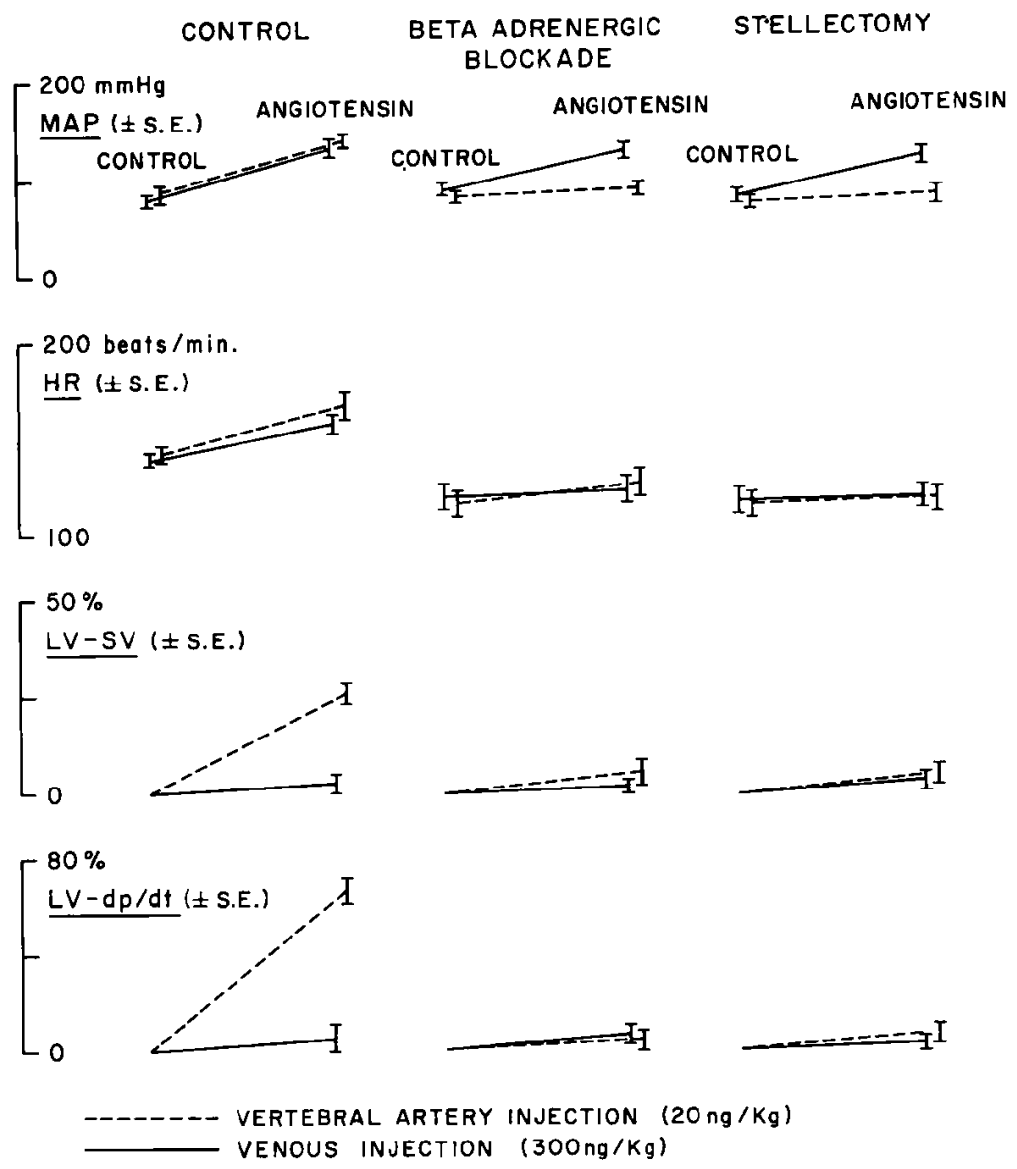

Fig. 4. This compares the effect of beta adrenergic blockade and bilateral stellectomy on the changes in heart rate (HR), stroke volume (LV-SV) of the left ventricle and $\mathrm{LV}$-dp/dt following angiotensin, doses which provide an equipressor response, given intravenously and into vertebral artery. MAP= mean systemic arterial pressure.

was abolished by these sympatholytic procedures. These results were also associated with the elimination of the increase in heart rate, stroke volume and $\mathrm{dp} / \mathrm{dt}$ of the left ventricle which occurred following vertebral artery angiotensin. The intravenous pressor effect, however, was not altered.

\section{C: Effect of Angiotensin on Carotid Occlusion Pressor Response}

The results obtained in Group 3 are shown in Fig. 5. In this figure changes in heart rate, stroke volume and $\mathrm{dp} / \mathrm{dt}$ of the left ventricle during bilateral carotid artery occlusion alone were compared to carotid occlusion 30 $\mathrm{sec}$ following intravenous and $10 \mathrm{sec}$ after the vertebral artery injections.

Carotid occlusion alone increased mean systemic arterial pressure by 


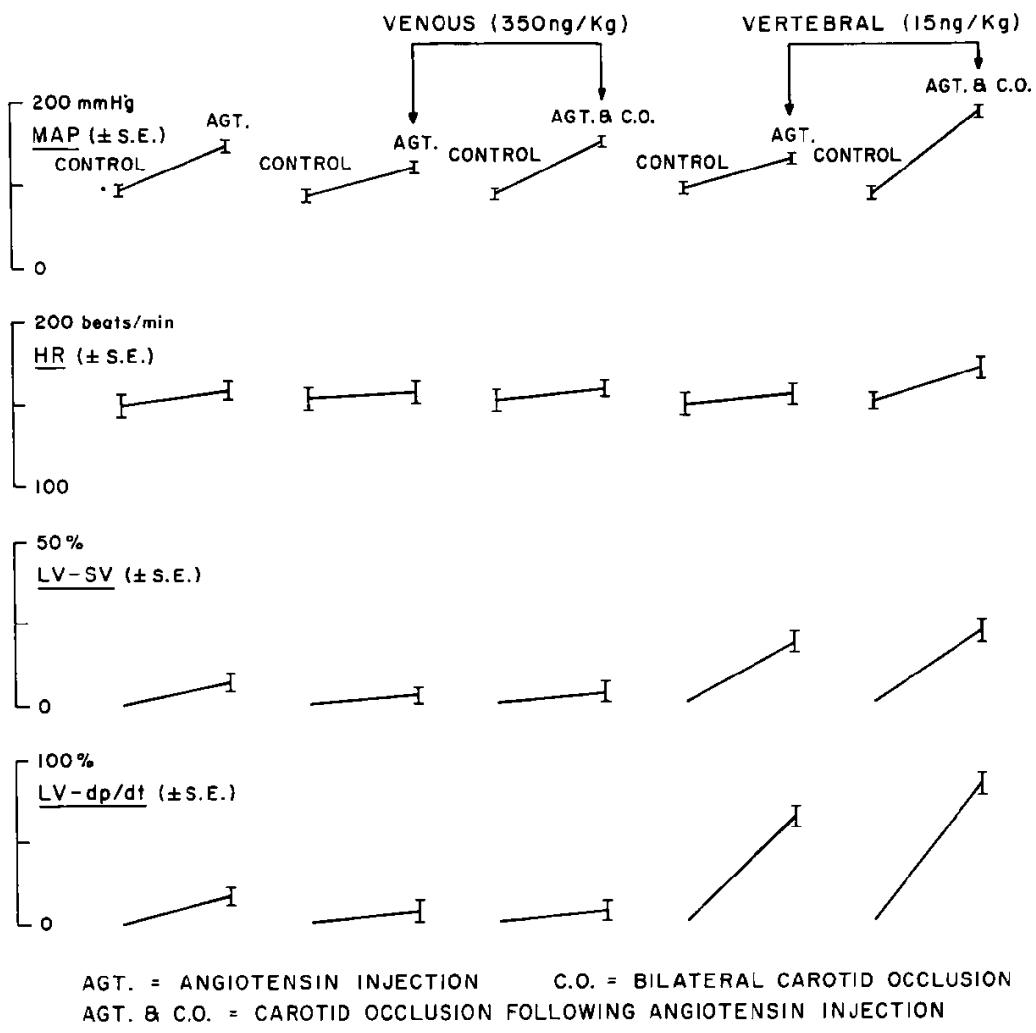

Fig. 5. The changes in mean systemic arterial pressure (MAP), heart rate (HR), left ventricular stroke volume (LV-SV) and LV-dp/dt during carotid occlusion alone (first column) are compared to those by angiotensin alone, equipressor doses given intravenously and into vertebral artery, and to those by carotid occlusion following angiotensin (third and fifth column).

$57 \mathrm{mmHg} \pm 7.3 \mathrm{SE}$, which was associated with $6 \% \pm 0.7 \mathrm{SE}$ increase in stroke volume and $16 \% \pm 1.1 \mathrm{SE}$ increase in $\mathrm{dp} / \mathrm{dt}$ of the left ventricle. The changes in heart rate were insignificant. Carotid occlusion following intravenous angiotensin increased the arterial pressure by $68 \mathrm{mmHg} \pm 6.1 \mathrm{SE}$, with no significant changes in heart rate, stroke volume and $\mathrm{dp} / \mathrm{dt}$. Carotid occlusion following vertebral artery angiotensin produced an increase $(92 \mathrm{mmHg} \pm$ $6.8 \mathrm{SE}$ ) in the arterial pressure. This response was associated with an increase in heart rate, stroke volume and $\mathrm{dp} / \mathrm{dt}$. The increases in stroke volume and $\mathrm{dp} / \mathrm{dt}$ were not significantly different from those which occurred from angiotensin alone into the vertebral artery, but the increase in heart rate was significantly greater $(\mathrm{p}<0.05)$. Although not shown in this figure, the potentiation of the carotid occlusive pressor response by intravertebral artery angiotensin was abolished in dogs pretreated with propranolol. 


\section{Discussion}

The present study has demonstrated that angiotensin doses ranging from 15 to $50 \mathrm{ng} / \mathrm{Kg}$ administered into either vertebral artery, produces a consistent rise in systemic arterial pressure. Failure to produce a pressor effect using similar intravenous or intra-carotid artery injection does support the previous view $\left.\left.{ }^{11}\right), 23\right), 24$ ) that there is a centrally mediated pressor action of angiotensin, which reacts in an area of the distribution of the vertebral artery.

The mechanism of this central nervous system action of angiotensin is different from that which follows larger intravenous angiotensin doses sufficient to raise arterial pressure. These intravenous angiotensin doses, although capable of producing an equipressor response, would appear to cause an overall increase in peripheral vascular resistance, since the cardiac output and heart rate are either unchanged or reduced ${ }^{25), 26)}$ as confirmed in the present study. This intravenous angiotensin action on vascular smooth muscle and subsequent pressor effect must be modified by a number of other demonstated effects. The direct chronotropic and inotropic action of angiotensin on the heart, ${ }^{27-30}$ ) however, might be masked by baroreceptor reflex reduction of sympathetic tone and direct coronary vasoconstriction. ${ }^{25), 29)}$ Modification of the pressor response to intravenous angiotensin can also occur by factors operating in the peripheral circulation. Stimulation of peripheral alpha adrenergic vasoconstrictor mechanism has been suggested by Page and McCubbin $^{51,6)}$ who observed an augmentation of pressor response to tyramine or carotid occlusion during infusion of angiotensin intravenously. Although the tyramine and carotid occlusion responses are thought to be mediated primarily through the alpha adrenergic system, these authors did not study the central circulation for a possible beta adrenergic influence on the augmented increase in blood pressure. Augmentation of the pressor response to carotid occlusion by intravenous angiotensin was also confirmed in the present study, and others. $^{31}$ ) In addition, the failure of beta adrenergic blockade and bilateral stellectomy to alter the intravenous pressor effect, or influence the augmentation of carotid occlusion pressor response by intravenous angiotensin, are further evidence in favor of a predominant alpha adrenergic stimulatory effect of intravenous angiotensin.

The doses of angiotensin required for a pressor effect when given intravenously produce concentrations many times larger than the angiotensin concentration which circulate under normal physiological conditions. Angiotensin doses small enough to produce changes in concentration within the physiological range ${ }^{22,24)}$ can produce changes only when they are injected into the vertebral artery. ${ }^{24}$ ) The present study has demonstrated the ability of physiologi- 
cal doses of angiotensin injected into the vertebral artery to produce an increase in stroke volume, heart rate, myocardial contractility and thus cardiac output. An explanation for the increase in stroke volume might be that greater (shortening of the systolic periods of both ventricles, and subsequent) prolongation of diastolic filling periods promoted an increase in ventricular residual volume as well as end diastolic pressure, which produced an increased stroke volume through the Frank-Starling mechanism. The stroke volume could have been augmented by an increased ventricular contraction velocity with more complete ventricular emptying. Neurogenic vasodilatation $^{2}$ ) or venoconstriction, ${ }^{32)}$ factors responsible for increasing systemic venous return, cannot, however, be excluded as contributors to the cardiac output rise. In any case we have found no evidence to support the previously held view $^{3,4,19)-13}$ ) that the central stimulation of the alpha adrenergic mechanism is solely responsible for this pressor effect.

Severs and his associates ${ }^{10}$ ) have postulated that this centrally mediated effect of angiotensin is sympathetic in nature involving alpha and beta adrenergic mechanisms. This is based on their observation of an increased heart rate and contractile force of the nictitating membrane of the cat, ${ }^{9)}$ occurring in association with the pressor effect of angiotensin $(4 \mu \mathrm{g} / \mathrm{Kg})$ administered into the perfused lateral ventricle of the brain. Recently, Scroop and Lowe ${ }^{24}$ have reported that the pressor response to angiotensin $(0.5$ to $32 \mathrm{ng} / \mathrm{min})$ infused into the vertebral artery was accompanied by an augmented cardiac output and a lowered peripheral vascular resistance. Since these findings were abolished by atropine, they postulated that the centrally mediated effect is a consequence of withdrawal of vagal tone and that augmentation of sympathetic tone is of minor importance. The results of the present study obtained in the vagotomized dogs support the view that intravertebral artery angiotensin activity is mediated via the sympathetic nervous system. Differences in results could be related to the differences in angiotensin doses, techniques of administration, or the differences between vagotomy and atropine to produce vagal blockade.

Observations in the present study also indicate that the centrally mediated pressor activity of angiotensin predominantly involves the beta adrenergic mechanism. Abolition of the centrally mediated pressor effect by beta adrenergic blockade or bilateral stellectomy supports this view. This theory is enhanced by the results in dogs pretreated with propranolol, in which the carotid occlusion pressor augmentation of intravertebral artery angiotensin was abolished.

The mechanism for the selective response of the right ventricle following angiotensin doses of 5 to $10 \mathrm{ng} / \mathrm{Kg}$ given into the vertebral artery is difficult to 
explain. The response might be due to neurogenic pulmonary vasoconstriction or an increase in systemic venous return. The former could not be demonstrated using a constant cardiac output right heart bypass preparation in 2 dogs. Using a sensitive low level strain gauge, no significant rise in right atrial pressure was observed, which suggest no singnificant increase in systemic venous return occurred. This raises the possibility that the centrally mediated actions of angiotensin may involve an integrated area of the brain with different sensitivities for functionally different circulatory areas. ${ }^{33 \text { ) }}$

In summary the evidence obtained in the present study suggest that the centrally mediated pressor activities of angiotensin operate by stimulation of the sympathetic nervous system, especially beta adrenergic sites. In contrast to the intravenous response, this activity involves the central circulation to a greater extent than the peripheral. It seems possible to speculate that the central nervous system effects of angiotensin may play a role in the augmented cardiac output found in the chronic stage of Goldblatt animals ${ }^{34)}$ and renovascular hypertension in man, ${ }^{351}$ and may participate in the normal physiologic control of cardiac output and blood pressure regulation.

\section{REFERENCES}

1. Feldberg W, Lewis GP: J. Physiol 171: 98, 1964

2. Laverty R: J. Pharm Pharmacol 15: 63, 1963

3. Bickerton RK, Buckley JP: Proc Soc Exp Biol 106: 834, 1961

4. Halliday RP, Buckley JP: Intern J Neuropharmacol 1: 43, 1962

5. McCubbin JW, Page IH: Circulat Res 12: 553, 1963

6. McCubbin JW, Page IH: Science 139: 210, 1963

7. Lewis GP, Reit E: J Physiol 179: 538, 1965

8. Zimmerman BG, Gomez J: Intern J Neuropharmacol 4: 185, 1965

9. Smookler HH, Severs WB, Kinnard WJ, Buckley JP: J. Pharm Exp Therap 153: 485, 1966

10. Severs WB, Daniels AE, Smookler HH, Kinnard WJ, Buckley JP: J Pharm Exp Therap 153: 530,1966

11. Yu R, Dickinson CJ: Lancet 2: 1276,1965

12. Scropp GC, Walsh JA, Whelan RF: Clin Sci 29: 315, 1965

13. Scroop GC, Whelan RF: Clin Sci 30: 79, 1966

14. Morrison JFB, Pickford M: J Physiol 202: 37, 1969

15. Scroop GC, Whelan RF: Aust J Exp Med Sci 46: 563, 1968

16. Aars H, Akre S: Acta Physiol Scand 74: 134, 1968

17. Finch L, Leach GDH: Brit J Pharmac 36: 481, 1969

18. Coan JW, Rovner DR, Cohen EL: Ann Int Med 63: 266, 1965

19. Dustan HP, Tarazi RC, Frohlich ED: Girculation 41: 555, 1970

20. Dickinson CJ, Lawrence JR: Lancet 1: 1354, 1963

21. McCubbin JW, Demoura RS, Page IH, Olmsted F: Science 149: 1394, 1965

22. Hodge RL, Lowe RD, Vane JR: J. Physiol 185: 613, 1966

23. Cranston WI, Laverty H, Lowe RD, Rosendorff C: J Physiol 198: 30, 1968

24. Scroop GC, Lowe RD: Nature 220: 1331,1968

25. Ross G: Cardiovasc Res 1: 255, 1967 
26. Krasney JA: Am J Physiol 215: 1454, 1968

27. Krasney JA, Thompson JL: Am J Physiol 213: 134, 1967

28. Koch-weser J: Circulat Res 16: 230, 1965

29. Fower NO, Holmes JC: Circulat Res 14: 191, 1964

30. Farr W, Grupp G: J Pharm Exp Therap 156: 528, 1967

31. Edmondson PC, Joels N: J Physiol 202: 82, 1969

32. DePasquale N, Burch GE: Circulat Res 13: 239, 1963

33. Ueda H, Inoue K, Iizuka M, Iizuka T, Ihori M, Yasuda H: Jap Heart J 7: 318, 1966

34. Olmsted F, Page IH: Circulat Res 16: 135, 1965

35. Frohlich ED, Ulrych M, Tarazi RC, Dustan HP, Page IH: Circulation 35: 289, 1967 